PROBLEMS

OF MANAGEMENT IN THE $21{ }^{\text {st }}$ CENTURY Vol. 11, No. 1, 2016

\title{
LOCUS OF CONTROL IN GEORGIAN TEACHERS AND ITS RELATION TO TEACHER BURNOUT
}

\author{
Maya Bitsadze, Marine Japaridze \\ Ilia State University, Tbilisi, Georgia \\ E-mail: maia.bitsadze@iliauni.edu.ge, marine_japaridze@iliauni.edu.ge
}

\begin{abstract}
The intensive reforms taking place in general education field in Georgia impose considerable stress to those engaged in teaching profession. This may gradually lead to the condition of professional burnout of teachers. According to the conducted research some teachers have experienced burnout while others did not. The purpose of the present research is to identify how the personal quality such as control of locus may have influenced the level of burnout in Georgian teachers. Two self-assessment instruments, Rotter Scale and Maslach Burnout Inventory (MBI), were used in this research to measure control of locus type and level of burnout among Georgian teachers. Two questionnaires were distributed among 407 teachers at Public schools of Georgia. After dismissing inaccurately filled out questionnaires the analysis was conducted based on the data received from 373 questionnaires. The research findings revealed that Georgian teachers with internal locus of control are less likely to become professional burnout victims. Significant correlations proved to exist between locus of control orientation and teacher burnout on Emotional Exhaustion (EE) and Personal Achievements (PA) subscales of MBI. The article explores the opportunities to change locus of control from external to internal as a part of teacher professional development activities guided by school Principals and through redesigning of teacher preparation programs in order to make teachers more resistant to professional burnout.
\end{abstract}

Key words: teacher burnout, locus of control, teacher preparation programs.

\section{Introduction}

During the centuries people discussed whether a person controls own life or not, what determines success - a fate or a free will? Julian B. Rotter intensively worked on locus of control topic (Rotter, 1966) and by means of creating the instrument for measuring locus of control in 1966 he managed to differentiate people with Internal and External locus of control. People who rely on the idea that they do not have control over own life (having External locus of control) justify own failure and underachievement by this factor. A great number of research on this topic states, that having Internal locus of control is closely related with the positive aspects of life, such as: success in sports, effectiveness at workplace, happiness and socialeconomic status.

\section{Problem of Research}

The concept of locus of control was further explored by other researchers. Kormanik and Rocco tried to explain the differences between internal and external locus of control by the peoples' perceptions of rewards and punishments. People with internal locus of control consider that rewards as well as punishments are related to personal behavior and actions, 
whereas people with external locus of control believe that their fate is managed by external forces (Kormanik \& Rocco, 2009).

Buriel and Rivera (1980) studied white and Spanish origin secondary school students by means of Rotter scale instrument. Differences were identified not in their ethnic origin, but in their socio-economic status. Those having low socio-economic status had external locus of control and those with high socio-economic status had internal locus of control (Buriel \& Rivera, 1980). Relation between success and internal locus of control was proved by other research as well conducted on college students (Denny \& Steiner, 2009).

It is an interesting question how stable personal quality is locus of control. Is it possible to change it through various life experiences? Early work of psychologists argued that a variety of personality traits develop before or during adolescence and then remain relatively stable from age 30 onwards (e.g. McCrae \& Costa, 2006; Costa \& McCrae, 1988). The extent to which personality can be considered stable is more contested today, with some psychologists suggesting that personality changes may occur up until the age of 50, depending on which specific personality trait is considered (e.g. Roberts, Walton, Viechtenbauer, 2000).

Schmitz and Skinner were working on these issues and with Rotter scale instrument they surveyed seventh grade students in Germany. Their findings showed that locus of control can be changed from external to internal and vice versa depending on teacher's feedback. If teacher or parent praised student for diligent work despite the received result, their locus of control remained the same or was becoming more internal. While fulfilling the next task students were showing the same or more diligence (Schmitz \& Skinner, 1993). According to the findings of this research, not taking into account students' efforts, can lower students' academic success and shift their locus of control to external dimension.

Researchers wanted to find out if internal locus of control was a predictor of success and prove that it was a stable personal quality. This research was in contradiction with the research seeing locus of control as a changeable quality according to the situations. Some researchers with Rotter scale surveyed school students' locus of control together with their GRE and socialeconomic status and used locus of control as a predictor of their continuation of studies at university level (Nordstrom \& Segrist, 2009). Positive correlation between internal locus of control and continuation of studies at university level was proved in this research.

Using locus of control as a means of prediction suggests an opinion that this personal quality, internal or external, may lead our actions to success or failure. Munir and Sajid (2010) also connected locus of control with organizational commitment of university professors in Pakistan. The research suggested that professional orientation of professors and locus of control plays an important role in contributing to university professors' affective commitment. Professors with more internal locus of control are more likely to have high affective and normative commitment, whereas participants with more external locus of control are more likely to have high continuance commitment.

The intensive reforms aiming at improving existing teaching and learning practices require higher levels of professionalism from teachers to stay in the profession. New requirements impose considerable stress to those engaged in teaching. This may gradually lead to the condition of professional burnout of teachers. According to the conducted research (Bitsadze \& Japaridze, 2014), some teachers have experienced a high level of burnout on Emotional Exhaustion (EE) subscale (23.7\%) and on Personal Achievements (PA) subscale (16.8\%), while the others did not. It was interesting to find out if a personal quality such as locus of control have influenced teachers to be protected and be less vulnerable to burnout. 
Maya BITSADZE, Marine JAPARIDZE. Locus of control in Georgian teachers and its relation to teacher burnout

PROBLEMS

OF MANAGEMENT

IN THE $21^{\text {st }}$ CENTURY

Vol. 11, No. 1,2016

10

\section{Research Focus}

A number of researchers aimed to identify correlations between professional burnout and locus of control (externality/internality). Research was conducted among 290 teachers in Turkey proved that teachers' external locus of control and age were in positive correlation with professional burnout subscales such as Emotional Exhaustion (EE) and Depersonalization (DP) (Sunbul, 2001). Similar results were received in earlier studies as well (Rahim, 1996; Leung $\&$ Spector, 2000; Sari, 2000). Teachers with internal locus of control had more positive selfperceptions (Sari, 1993); Evans \&Coman (1993); Brouwers \&Tomic, 2000). Teachers' external locus of control was also found to be negatively correlated with Personal Accomplishment (PA) scale of burnout (Lunenburg \& Cadavid, 1992). Internals are less frequently experiencing burnout because they have more control over the environment (Whitebook, Howes, Darrah, Friedman, 1982).

The studies conducted on locus of control suggest that it has an impact on burnout. Despite relative stability of this personal quality, some research claimed that it is possible to change it through using of various methods.

The purpose of the present research was to prove that personal quality such as locus of control could have an impact on teacher burnout and locus of control type correlates with teacher burnout levels.

\section{Methodology of Research}

\section{General Background of Research}

In the light of the literature discussed in the previous section, the present research intended to test the following hypothesis:

- $\mathrm{H}_{01}$ Locus of control type and burnout are in correlation;

- $\mathrm{H}_{02}$ Teachers with external locus of control show positive correlation on all

three scales of burnout levels (Emotional Exhaustion, Depersonalization and Personal Achievements);

- $\mathrm{H}_{03}$ Teachers with internal locus of control are less vulnerable to professional burnout.

Research was conducted in 2012-13 among teachers working in the public schools of Georgia. Among the possible limitations of the research can be named that the larger sample was desirable. In this case, it may be possible to see the correlations with other factors as well (level of education teaching level, social condition, etc.).

It should also be noted, that researching professional burnout is a very sensitive issue. As the research was anonymous, it was impossible to research teacher burnout or locus of control together with teacher achievement or their students' achievements, School Principals' managerial style and other factors of teacher effectiveness. In this research, analysis was based only on teachers' self- report, regarding their burnout or locus of control.

\section{Sample of Research}

The sample of the research was derived from a pool of teachers working at Georgian public schools. Two questionnaires were distributed among 407 teachers at a centralized training venue attended by teachers from various regions and were representing urban and rural, small, medium and large schools. After dismissing inaccurately filled out questionnaires, the analysis was conducted based on the data received from the duly filled out questionnaires submitted by 373 teachers. 


\section{Instrument and Procedures}

Two the most popular and tested instruments for reliability and validity were used for this research: Rotter's Control of Locus Scale (Rotter, 1966) and Maslach's MBI-ES (Maslach, MBI-ES, 1996). Rotter's Control of Locus Scale consisted of 29 statements. Each statement had $\mathrm{a}$ and $\mathrm{b}$ answer option to be selected by the respondent. Among other existing instruments for researching locus of control (E.g. Crandall Intellectual Ascription of Responsibility Scale or the Nowicki-Strickland Scale) Rotter's Scale instrument was selected as it was already adapted on Georgian population.

Christina Maslach's MBI-ES was used to identify teacher burnout subscales and burnout degree. MBI-ES consists of 22 statements on which respondents self -assess own attitude on 6 step scale. The instrument was translated from English into Georgian, tested on a small group and its validity and reliability was tested by using Cronbach's alpha.

The survey questionnaires were distributed among 407 teachers. Analysis was made on 373 questionnaires. 34 questionnaires were dismissed, due to incompleteness/inaccuracy.

Teacher participation in the survey was voluntary and anonymous, as it was required by the test administration procedures.

\section{Data Analysis}

Descriptive and correlation research analysis was used in the current research. SPSS (PASW Statistics 21) was used for processing the results.

\section{Results of Research}

According to the research results on Figure $1.46 \%$ of the survey, Georgian teachers had Internal locus of control, Mixed type were $42 \%$ and $12 \%$ of teachers had External locus of control.

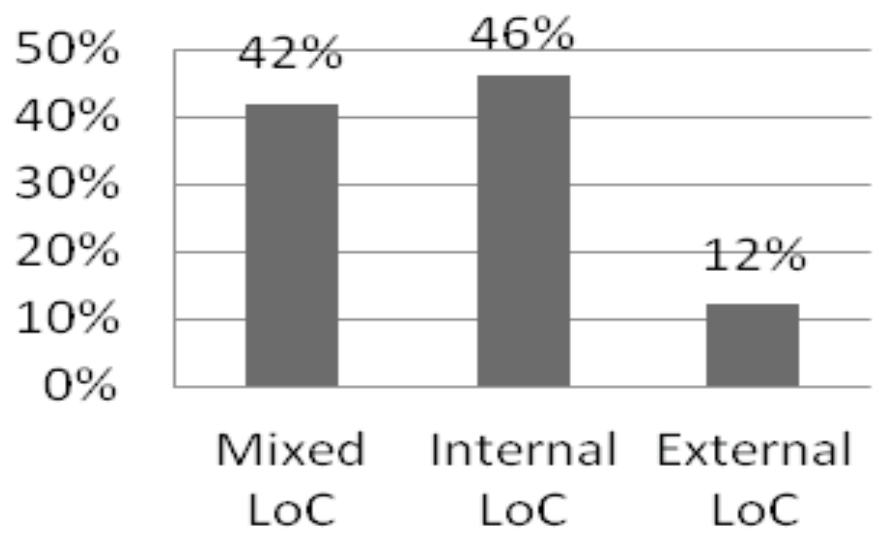

\section{Figure 1: Surveyed teachers according to locus of control.}

Table 1 shows locus of control according to internal teacher groups (strongly expressed externality, weakly expressed externality, mixed type, strongly expressed internality and weakly expressed internality). In the surveyed teachers majority among the surveyed teachers had mixed locus of control (41.8\%) and weakly expressed internals (33.8\%). As for externals, strongly expressed externals comprise $3.5 \%$ and weakly expressed externals - $8.8 \%$. 
Maya BITSADZE, Marine JAPARIDZE. Locus of control in Georgian teachers and its relation to teacher burnout

PROBLEMS

OF MANAGEMENT

IN THE $21^{\text {st }}$ CENTURY Vol. 11, No. 1, 2016

Table 1. Teacher groups according to control of locus.

\begin{tabular}{lll}
\hline Locus of Control Types & Number of responses & $\%$ \\
\hline Strongly expressed Externality & 13 & 3.50 \\
\hline Weakly expressed Externality & 33 & 8.80 \\
\hline Mixed type & 156 & 41.80 \\
\hline Strongly expressed Internality & 45 & 12.10 \\
\hline Weakly expressed Internality & 126 & 33.80 \\
\hline
\end{tabular}

Analysis also stated that statistically reliable correlation exists between locus of control and professional burnout two subscales: Emotional Exhaustion (EE) and Personal Accomplishments Reduction Scale (PA). EE ( $r=0.193 ; \mathrm{p}<0.001)$ and PA $(\mathrm{r}=-0.150 ; \mathrm{p}<0.004)$.

Control of locus correlation with Professional Depersonalization subscale was not proved.

Control of Locus groups were compared to the three subscale groups of burnout. The results of control of locus group comparison with professional burnout (EE) subscale groups are shown in Table 2.

Table 2. Locus of Control Groups and EE levels.

\begin{tabular}{|c|c|c|c|c|c|c|}
\hline & & & EE -E & Exhaustio & & Tatal \\
\hline & & & High & Medium & Low & Iotal \\
\hline & & Frequency & 18 & 11 & 16 & 45 \\
\hline & External & $\begin{array}{l}\% \text { locus of } \\
\text { control-united }\end{array}$ & 40.0 & 24.4 & 35.6 & 100.0 \\
\hline & & $\% \mathrm{EE}$ & 18.9 & 11.7 & 8.7 & 12.1 \\
\hline & & Frequency & 45 & 42 & 69 & 156 \\
\hline Locus of & Mixed type & $\begin{array}{l}\% \text { locus of } \\
\text { control-united }\end{array}$ & 28.8 & 26.9 & 44.2 & 100.0 \\
\hline Control- & & $\%$ EE & 47.4 & 44.7 & 37.7 & 41.9 \\
\hline united & & Frequency & 32 & 41 & 98 & 171 \\
\hline & Internal & $\begin{array}{l}\% \text { locus of } \\
\text { control-united }\end{array}$ & 18.7 & 24.0 & 57.3 & 100.0 \\
\hline & & $\% \mathrm{EE}$ & 33.7 & 43.6 & 53.6 & 46.0 \\
\hline
\end{tabular}

As the results show, teachers having External locus of control in Emotional Exhaustion (EE) groups, showed the highest level of emotional exhaustion - 18.9\%. Teachers, having a mixed type of control locus, showed high Emotional Exhaustion (EE) - $47.4 \%$. In teachers with internal locus of control 53.6\% showed the lowest level of emotional exhaustion.

According to the received results, it can be concluded that from the three groups, the teachers having External locus of control, are more prone to emotional exhaustion than teachers having Internal locus of control.

On Personal Accomplishments (PA) scale, teachers with External locus of control received the highest score $(14.5 \%)$. 
Table 3. Locus of Control Groups and PA Levels.

\begin{tabular}{|c|c|c|c|c|c|c|}
\hline & & & \multicolumn{3}{|c|}{ PA - Personal Accomplishments } & \multirow{2}{*}{ Total } \\
\hline & & & High & Medium & Low & \\
\hline & \multirow{3}{*}{ External } & Frequency & 12 & 11 & 22 & 45 \\
\hline & & $\%$ locus of control-united & 26.7 & 24.4 & 48.9 & 100.0 \\
\hline \multirow{7}{*}{$\begin{array}{l}\text { Locus of Control- } \\
\text { united }\end{array}$} & & $\% \mathrm{PA}$ & 17.4 & 14.5 & 9.9 & 12.3 \\
\hline & & Frequency & 37 & 34 & 82 & 153 \\
\hline & Mixed type & $\%$ locus of control-united & 24.2 & 22.2 & 53.6 & 100.0 \\
\hline & & $\% \mathrm{PA}$ & 53.6 & 44.7 & 36.9 & 41.7 \\
\hline & \multirow{3}{*}{ Internal } & Frequency & 20 & 31 & 118 & 169 \\
\hline & & $\%$ locus of control-united & 11.8 & 18.3 & 69.8 & 100.0 \\
\hline & & $\% \mathrm{PA}$ & 29.0 & 40.8 & 53.2 & 46.0 \\
\hline
\end{tabular}

As for teachers with mixed type locus of control, they showed the highest percent for personal accomplishments reduction (PA) - 53.6\%

Teachers with internal locus of control showed the lowest percent in personal achievements reduction $53.2 \%$.

According to the received results, it can be concluded that the teachers having internal locus of control are less likely to suffer from reduction of personal accomplishments and those with External locus of control are more susceptible to burnout.

\section{Discussion}

The presented research findings are in line with the research results received by other researchers claiming that teachers with internal locus of control are less likely to become professional burnout victims. Correlation of external locus of control and burnout was also proved to be true, though for only on two subscales of burnout: Emotional Exhaustion (EE) and Personal Accomplishments (PA).

In some research, internal locus of control was used as a predictor of future success, having less vulnerability to burnout, serving for improving employee commitment to organization and professional effectiveness. These factors should not be overlooked by school administrators, leading teacher professional development and by teacher preparation programs, preparing teachers for a very complex and demanding profession. Teacher preparation programs in Georgia are offered by several public and private universities and governmental agencies. Some non-governmental organizations also are running teacher professional development programs. Few programs have paid due attention to elements of personal qualities, identifying teacher fit to the profession and development of needed qualities during professional development. In particular, identification of teacher locus of control and work on its gradual change through various means: informing, exercises, learning experiences and other activities may be beneficial for future teachers.

The research findings on relative stability of locus of control and the possibility to change it even in adulthood, as proved by recent studies, seems to be very important and can be used for improving teacher preparation programs as well as by school Principals, so that clear award and motivation systems for teachers exist at schools. More attempts should be taken to change 
Maya BITSADZE, Marine JAPARIDZE. Locus of control in Georgian teachers and its relation to teacher burnout

PROBLEMS

OF MANAGEMENT

IN THE $21^{\text {st }}$ CENTURY Vol. 11, No. 1, 2016

teacher locus of control from external to internal so that when teachers start their pedagogic career at schools they become less vulnerable to professional burnout.

The research also indicates the need for improving teacher socio-economic status and introducing mechanisms for teacher support at schools as these factors are in close correlation to strengthening of internal locus of control in teachers for improving their commitment to teaching profession and schools. This research adds more proofs to the statements made on teacher burnout and locus of control correlation by the researchers in various countries. The same correlations and actuality of these issues were confirmed in Georgian context as well.

\section{Conclusions}

On the base of the research, it can be concluded that significant correlations exist between teacher locus of control orientation and burnout on EE and PA subscales of MBI in Georgian context. Teachers with internal locus of control are less vulnerable to professional burnout and may lead longer and successful pedagogical career.

The research findings can be useful for teacher preparation programs administered by the universities and governmental agencies in order to improve their effectiveness and assist teachers to gradually change their control of locus orientation from external to internal. On the other hand, school administrators also may find research findings valuable and ensure that teacher motivation, success recognition and award systems and mechanisms are in place at schools.

The research findings are significant, however, it should be noted that research on locus of control and teacher burnout still is very limited and there is a need for conducting further longitudinal studies on larger samples.

\section{References}

Bitsadze, M., \& Japaridze, M. (2014). Personal and social aspects of teacher burnout in Georgia. Problems of Education in the 21st Century, 59, 7-14.

Brouwers, A., \& Tomić, W. (2000). A longitudinal study of teacher burnout and perceived self-efficacy in classroom management. Teaching and Teacher Education, 16, 239-254.

Buriel, R., \& Rivera, L. (1980). The relationship of locus of control to family income and familism among Anglo and Mexican-American high school students. The Journal of Social Psychology, 111, 27-34. Retrieved from http://www.tandfonline.com/doi/abs/10.1080/00224545.1980.99242 69\#.UeAiTW1qjac.

Cobb-Clark, D., \& Schurer, S. (2011). Two economists' musings on the stability of locus of control. Institute for the Study of Labor, IZA Discussion Paper No. 5630, April.

Costa, P., \& McCrae, R. (1988). Personality in adulthood: A six-year longitudinal study of self-reports and spouse ratings on the NEO personality inventory. Journal of Personality and Social Psychology, $54,853-863$.

Evans, B. J., \& Coman, G. J. (1993). General versus specific measures of occupational stress: An Australian police survey. Stress Medicine, January, 11-20.

Kormanik, M., \& Rocco, T. (2009). Internal versus external control of reinforcement: A review of the locus of control construct. Human Development Review, 8, 436-483.

Leung, T., Siu, O., \& Spector, P. E. (2000). Faculty stressors, job satisfaction, and psychological distress among university teachers in Honk Kong: The role of locus of control. International Journal of Stress Management, 7 (2), 121-38.

Lunenburg, F. C., \& Cadavid, V. (1992). Locus of control, pupil control ideology, and dimensions of teacher burnout. Journal of Instructional Psychology, 19 (1), 13. 
Maslach, C., Jackson S., \& Leiter, M. P. (1996). Maslach burnout inventory manual, Third Edition, Mountain View, California, CPP, Inc

McCrae, R., \& Costa, P. (2006). The stability of personality: Observation and evaluations. Current Directions in Psychological Science, 132, 1-25.

McIntyre, T. C. (1984). Teacher stress and burnout: A review of research literature. Information Analysis, (ERIC Document No. ED. 236 868).

Munir, S., \& Sajid, M. (2010). Examining locus of control (LOC) as a determinant of organizational commitment among university professors in Pakistan. Journal of Business Studies Quarterly, 1 (3), 78-93. Retrieved from http://jbsq.org/wp-content/uploads/2010/10/JBSQ 4F.pdf.

Nordstrom, C. R., \& Segrist, D. J. (2009). Locus of control predicts likelihood of pursuing graduate studies. College Student Journal, 43 (1), 200-206.

Rahim, A. (1996). Stress, strain, and their moderators: An empirical comparison of entrepreneurs and managers. Journal of Small Business Management, 34 (1), 46-58.

Roberts, B. W., Walton, K. E., \& Viechtenbauer, W. (2000). Patterns of mean-level change in personality traits across the life course: A meta-analysis of longitudinal studies. Psychological Bulletin, 126, $3-25$.

Sari, H. (1993). Social and emotional problems of deaf adolescents in Turkey (Unpublished MA Thesis), England: University of Warwick.

Sari, H. (2000). An analysis of the policies and provision for children with special educational needs in England and Turkey (Unpublished EdD Thesis). England: Oxford Brookes University, Westminster Institute of Education.

Schmitz, B., \& Skinner, E. (1993). Perceived control, effort, and academic performance: Interindividual, intraindividual, \& multivariate time-series analyses. Journal of Personality and Social Psychology, 64, 1010-1028.

Sunbul, A. M. (2003). An analysis of relations among locus of control, burnout and job satisfaction in Turkish high schools teachers. Australian Journal of Education, 47 (1). Retrieved from https:// www.researchgate.net/publication/242607901_An_Analysis_of_Relations_among_Locus_of_ Control_Burnout_and_Job_Satisfaction_in_Turkish_High_School_Teachers.

Whitebook, M., Howes, C., Darrah, R., \& Friedman, J. (1982). Caring for the caregivers: Staff burnout in child care. In L. Katz (Ed.), Current topics in early childhood education, Ablex Publishing, Norwood, NJ, 57-79.

Advised by Sophia Gorgodze, Ilia State University, Tbilisi, Georgia

Received: May 25, 2016

Accepted: June 18, 2016

\begin{tabular}{|c|c|}
\hline Maya Bitsadze & $\begin{array}{l}\text { PhD., Associate Professor, llia State University, 3/5 Cholokashvili ave, Tbilisi } 0162 \text {, } \\
\text { Georgia. } \\
\text { E-mail: maia.bitsadze@iliauni.edu.ge } \\
\text { Website: http://www.lliauni.edu.ge }\end{array}$ \\
\hline Marine Japaridze & $\begin{array}{l}\text { PhD., Professor, llia State University, 3/5 Cholokashvili ave, Tbilisi 0162, Georgia. } \\
\text { E-mail: marine_japaridze@iliauni.edu.ge } \\
\text { Website: http://www.iliauni.edu.ge }\end{array}$ \\
\hline
\end{tabular}

